\title{
GENDER ANALYSIS OF ECONOMIC DEVELOPMENT IN COASTAL CITY
}

\author{
Priyo Utomo \\ Sekolah Tinggi Ilmu Ekonomi Pemuda
}

\begin{abstract}
The purpose of this study is gender economic development, labor force participation, unemployment, and education. The research method uses descriptive qualitative supported by quantitative data. The results of this study show that the community understood enough about the concept of gender, gender equality, and gender mainstreaming. Women and men seem to understand women better than men. This can be seen from the results of data analysis. In terms of the notion of gender, there are still varied opinions, signifying the struggle for a variety of understanding about gender concepts. In terms of whether or not they agree with gender equality, there are still those who disagree even though the number is small at $20.50 \%$, and when compared to that number, men are greater $(13.67 \%)$ than women (6.83\%). Most men mentioned this because women would no longer feel uncomfortable with men. From this, it can be said that there is still a patriarchal culture, which considers women to feel uncomfortable facing men, men should be more authoritative, than women, where it should not have happened if they understand the concept of gender. In the end, they are generally and conceptually aware of the concept of gender equality or gender mainstreaming. However, in reality, their perceptions are still influenced by the culture of male domination.
\end{abstract}

Keywords: gender, equality, justice, PUG

\section{INTRODUCTION}

The concept of gender is a trait that is inherent in men and women who are constructed socially and culturally (Meier \& Celis, 2011). For example, that woman is known to be gentle, emotional, beautiful, and motherly while men are considered strong, rational, and mighty. Changes in the characteristics of the traits can occur from time to time and from place to place, from social class to

\footnotetext{
*Corresponding Author.

e-mail: priyoutomo.stiepemuda@gmail.com
} 
other social classes. Gender Equality is the result of achieving one of the development goals in Indonesia, which is to create a just and prosperous society without differentiating between men and women. Although much development progress has been achieved, the reality shows that the gender gap still occurs in most fields of development, especially in the fields of education, health, and economy (DiPrete \& Buchmann, 2013).

The issue of gender inequality is what limits women's involvement in development and has an impact on achieving quality of life (Jha \& Nagar, 2015). This must be done from the perspective of gender-oriented development, where women and men, as members of the community, have the same position and rights to access, benefit, participate, and control the development. Measuring the success of human resource development is done through three indicators of development achievement, namely the Human Development Index (HDI), the Gender Development Index (IPG), and the Gender Empowerment Index (IPG). HDI is a composite indicator with several main variables, namely education, health, and economy. IPG measures achievement in the same dimension by looking at inequality and accommodating differences in achievement between men and women. Whereas the IGD measures the presence or absence of gender inequality in the economic field, political participation, and decision making (Ombati \& Ombati, 2012). This research will use secondary data that will be analyzed to obtain information and facts about gender equality in the Lamongan Regency government apparatus. The extent of this research is the existence of gender equality in the environment of government officials and in parts that still describe gender bias. The results of this study are very useful for adding concepts about gender and its dynamics. How far are the achievements of gender equality in the community and whether the Gender Mainstreaming (PUG) policies have been implemented in the community, especially at the local government apparatus as a community service institution? Therefore, this research is critical to be carried out (Dhewy, 2017).

\subsection{Gender Mainstreaming Policy}

The practice of gender inequality is still found in life, both social, economic, educational, and health. In order to achieve gender equality, the state must 
intervene by carrying out policies for development (Nie, 2010), defining PUG as a technical and political process that requires changes in the culture or character of the organization, objectives, structure, and allocation of resources. Meanwhile, according to the General Regulation of the Minister of Home Affairs Regulation No. $15 / 2008$, what is meant by PUG in the regions is a strategy built to integrate gender into an integral dimension of planning, drafting, implementing, monitoring, and evaluating development policies, programs, and activities in the regions. Thus, PUG is a strategy to realize KG, not an objective (Muchtar, Koban, Inayatullah, Srihadi, \& Amelia, 2012).

Gender Injustice (Problems)

\section{PUG} (Strategy)

\section{KG}

(Purpose)

\subsection{Gender Analysis Techniques}

Harvard Model Analysis or the Harvard Analysis Framework is developed by the Harvard Institute for International Development, in collaboration with the Office of Women in Development (WID)-USAID. The Harvard model is based on the WID efficiency approach, which is the earliest framework of gender analysis and gender planning (Okali, 2011). The Moser model analysis technique or the Moser Framework was developed by Caroline Moser (Okali, 2011), a senior researcher in gender planning. This framework is based on the Gender and Development (GAD) approach, which was built on the Women's in Development (WID) approach. This framework is sometimes referred to as the "Triple Roles Models.”

\section{RESEARCH METHODOLOGY}

This research uses descriptive qualitative supported by quantitative data (Maxwell, 2010). The scope of the study is reviewing and analyzing policies, 
programs, and activities of DPOs related to gender equality in the Lamongan Regency Government. Qualitative data tracking is done by collecting secondary data sourced from official/agency reports and data from statistical data about the condition of Lamongan Regency Government officials. This population includes economy, labor force participation rate, unemployment, and social aspects, which include aspects of education and health aspects. Also, interviews will be conducted with key people in the Lamongan District Government, to strengthen the statistical data, especially in supporting gender analysis.

\section{RESULTS AND DISCUSSION}

Whereas the total human development index (HDI) has increased as indicated by the value of HDI in 2010 amounting to 65.40 and increasing to 71.97 in 2018; the human development index on male gender shows an increase from 2010 reaching 71.56 and continues to increase to 77.03 in 2018; the human development index on female gender also showed an increase in 2010 at 58.26 and rose to 67.79 in 2018 . This shows that the growth of the women's HDI is less rapid than that of the men's HDI because there are still gaps in human achievements development between women and men. Nationally, the development of women is still lagging compared to men. From 2010, the development of men has a "high" status with an HDI above 70, while the development of women is still in the range of the 60s, and the status is “medium.”

The gender empowerment index in Lamongan Regency shows that the increase from 2010 reached 55.39 to 2014 reaching 68.75; while in 2015 it decreased to 67.30 and increased in 2017 to 68.10 and decreased again in 2018 to 67.95; whereas the women's empowerment index (IDG) can show whether women can actively participate in economic life. IDG focuses on participation by measuring gender inequality in the field of decision making and accessibility to economic resources. The condition of employment based on gender as seen from the unemployment rate shows a decline for men, namely in 2013, a rate of 4.31 and a decrease in 2018 to 2.37 and fluctuations for women in 2013 amounted to 5.74 and fell to 4.38 in 2014 and increased again in 2017 to 5.61 then decreased again in 2018 to 4.26. This is due to the existence of gender gap in 
the level of open unemployment experienced by women. This further shows the growing stereotype in society about the role of men as the main breadwinner as a dominant factor that limits women to work. Factors causing discrimination at work are marginalization at work, the situation of women who are subordinate in socio-culture, stereotypes towards women, and lower levels of education (Bhopal, 2019). However, access to education for a woman has improved over time, and it is hoped that an education level equal for men and women can be attained and thus participate in all sectors of the labor market. Labor conditions based on gender, labor force participation rate (TPAK), in Lamongan Regency in 2014-2018 experienced an increase in women in 2014 amounted to 49.71 and increased in 2018 amounted to 55.53; while for men the amount declined in 2017 to 84.74 and it fell again in 2018 by 81.62 . This is because the labor force is proxied by the level of male labor force participation (TPAK). The TPAK of women against men significantly influences economic growth in a positive direction. This increase in TPAK means a reduction in the gap between men and women at work. First, this is due to an increase in the participation of women in the workforce, where women are given greater flexibility and opportunity to work. Increasing female labor force participation does not reduce the level of male labor force participation, assuming the level of male participation remains. Secondly, the improvement of women's education opens opportunities for them to work and have a career.

The labor conditions based on the gender of job seekers in Lamongan Regency in 2013-2018 increased for men in 2013 to 863 and rose in 2018 to 1,684; whereas for women also experienced income in 2013 of 1,045 and rose again in 2018 of 1,226; this is because gender equality has become a social change. After all, it has changed the social structure in society. What used to be different between women and men, is now free and limited according to their roles and status in society. Gender equality has a positive impact, which is to develop women's creativity, talents, and abilities (Windels \& Mallia, 2015).

Gender-based labor conditions seen from migrant workers in Lamongan Regency in 2013-2018 experienced fluctuations for men. This can be seen in 2013 at 258; in 2014 amounted to 130; in 2015 amounting to 186, in 2016 amounting to 147; in 2017 amounted to 414 and in 2018 it fell to 287; whereas for women, it can be seen in 2013 that there were 53; in 2014 amounted to 22; 
in 2015 amounted to 300 , in 2016 amounted to 293; in 2017 amounted to 497 and in 2018 it fell to 113; it is concluded that the value of TKI for men in 2018 is still high compared to women of 113 , this shows that there is gender equality and gender justice in migrant workers and for women the implementation of the liberal feminism movement to show solutions to solve development problems, namely stopping marginalization of women by fighting for changes in laws and regulations that make it possible for women to have equal access and control to work and economic rewards (Grant, 2013).

The condition of education in Lamongan Regency based on gender in 20132018 has increased every year, this is evidenced from the educational index figures in men in 2013 that reached 0.632, and in 2018 it rose to 0.660; whereas for the index of education for women in 2010 it was 0.569 and rose in 2018 to 0.615 . This is because gender equality in education has been going well because of the efforts to stop gender bias in all aspects of life, among others, by meeting the practical needs of gender. The main strategy towards gender equality in education is the provision of access to quality education, especially basic education, equally for boys and girls both through school education and nonschool education and provision of access to equal education for adults who are unable to attend school education. Also, increasing the provision of literacy education services for the adult population, especially women, as well as improved coordination, information, and education to take care of genderoriented education and the development of educational institutions both at the central and regional levels regarding gender-oriented education (Jones \& Chant, 2009).

The life expectancy (AHH) of Lamongan Regency in 2013-2018 experienced a significant increase. This is evidenced by the life expectancy in 2014, which reaches 71.47 and rising in 2018, amounting to 72.04 . This is because genetically, women have a higher degree of health than men. This is known as female advantage (FA). The presence of female advantages is related to female hormones and women's life habits that are generally considered "healthier" than men. The implication of this is the life expectancy of women, especially in Indonesia, as always of higher value than men's. Although it is different, the tendency of UHH to grow annually is a warning for all groups to prepare facilities for the elderly whose numbers are predicted to increase shortly. 
Results of Respondents Analysis of Gender Equality. First, regarding the view on gender equality, the results of data processing showed that the views of respondents are also varied. Nearly half the respondents, $47.83 \%$ (31.68\% women, and $16.15 \%$ men) stated that gender equality is equal rights between women and men in society. Furthermore, almost half also, namely $37.89 \%$ of respondents $(22.98 \%$ female men $14.91 \%)$, stated that gender equality was a parallel between women and men, and the rest, $14.28 \%$ (women $8.70 \%$ and men $5.58 \%$ ) of the respondents stated that gender equality is no different between women and men in all fields.

From the findings above, it turns out that most respondents gave their views that gender equality is equal rights between women and men. Moreover, when disaggregated between men and women, it turns out that the acquisition of female respondents is greater than that of men. Second, regarding the view of gender inequality for respondents, from the data collected, it turns out that the majority of respondents of $67.70 \%(44.72 \%$ women and $22.98 \%$ men) stated that the view of gender inequality was the powerlessness of women in attitude compared to men. Then almost half of the respondents, $26.71 \%(16.77 \%$ women and $9.94 \% \mathrm{men})$, stated that gender inequality was the perception of win-lose between women and men, and the rest was 5.59\% (1.86\% women and $3.73 \%$ men) who stated an indifferent attitude of women towards their existence. From the findings above, it can be stated that the view of the majority of respondents regarding gender inequality is the powerlessness of women to behave compared to men. When compared between women and men, it turns out that the percentage acquisition for female respondents is greater than male respondents. Third, towards the view of agreeing or disagreeing with the concept of gender equality, it turns out that the majority of them, $79.50 \%$ of respondents (women $56.52 \%$ and men $22.98 \%$ ), agree with the concept of gender equality The rest, in the amount of $20.50 \%$, disagrees, the findings above can be obtained by the description that most respondents agreed with the concept of gender equality. Furthermore, if women and men were found to have a greater percentage of female respondents who agreed, compared to men. Fourth, from the reason for agreeing with the concept of gender, from the results of data processing, it turned out that $50 \%$ of respondents $(35.94 \%$ women and $14.06 \%$ men) gave reasons because there is a feeling of mutual support in all fields 
between women and men. The rest, 39.84\% of respondents (women 29.69\%, men $10.15 \%$ ), gave reasons because they were aware of their respective obligations. Moreover, $10.16 \%$ gave a reason for mutual respect between women and men.

From the findings above, it is obtained that most respondents agree with gender equality because there is a feeling of mutual support in all fields between women and men. Fifth, the reason for agreeing if women take much work in politics, was that $61.86 \%$ of respondents, ( $33 \%$ women and $17.53 \%$ men) gave reasons because there were equal rights between men and women, the rest was $34.02 \%$ (women $28.87 \%$ and men 5.15\%) who gave reasons because there would be no domination between women and men, and $4.12 \%$ gave reasons because women felt confident.

From the description above, it can be said that the majority of UPI students agree that if women take part in politics and nearly half of those who agree are women. The analysis given for their consent is mostly due to equal rights between men and women. Sixth, while the reasons do not agree if many women take part in politics, from the results of data processing, it turns out that the reason given is because it absorbs much time for family $(68.75 \%)$. This number came from $35.94 \%$ of women and $32.81 \%$ of men. Then $17.19 \%$ of respondents (men $14.06 \%$ and women $3.12 \%$ ) gave reasons because women's confidence was too prominent, and the rest $14.06 \%(9.38 \%$ men and women $3.12 \%)$ gave reasons for being physically and mentally tiring. From the description above, it can be stated that the number of respondents who disagreed mostly gave reasons for their disapproval that if women took part in politics, they absorbed a lot of family time. Meanwhile, when compared with women and men, the percentage of men is greater than women. Seventh, the opinion of the respondent if the wife's income is higher, from the results of data processing, it turns out that $44.72 \%$ of respondents $(22.98 \%$ of women and $18.01 \%$ of men) stated that they still hoped that their husbands would earn more. Then $40.99 \%$ (33.54\% of women and $11.18 \%$ of men) expressed their salute and pride, and the remaining $14.29 \%(7.46 \%$ of men and $6.83 \%$ of women) said that their wives were becoming arrogant.

From the findings above, it can be said that almost half of the respondents said they still hoped that the husband would earn more than his wife. Mean- 
while, when compared between women and men, it turns out that the percentage of women is greater than that of men. Eighth, the opinion of the respondent in the case if a woman becomes an official in an agency. From the results of data processing it turns out that $63.35 \%$ of respondents (i.e., $44.72 \%$ of women and $18.63 \%$ of men) expressed their respect and pride, then $33.54 \%(18.01 \%$ of women and $15.53 \%$ of men) expressed mediocrity, and the rest $3.11 \%(0.62 \%$ female and $2.49 \%$ male) stated that they were irritated and awkward about it. From the findings above, it can be said that respondents' answers varied. The most is expressing salute and pride when women become officials in an agency. Furthermore, when divided between women and men, it turns out that the percentage of women is greater than that of men. Ninth, the opinion of the respondents if in a family, the wife has a higher social position than the husband. From the results of data processing, it was found that $92.55 \%$ of respondents (59.63\% of female respondents and $32.92 \%$ of men) stated that the husband remained dominant as the head of the family, the rest, $6.83 \%(3.11 \%$ of women and $3.73 \%$ of men), stated that the wife is more dominant than the husband, and $0.62 \%(0.62 \%$ female respondents) stated that all decisions regarding family matters are determined by the wife.

From the findings above, it can be said that almost all respondents stated that if in a family the wife has a higher social position, she would still hope that the husband remained dominant as the head of the family. Moreover, when divided between women and men, it turns out that the percentage of women is also greater than the percentage of men. Tenth, in terms of whether or not women are given the same opportunities as men in development activities. From the results of processing the collected data, it turns out that $92.55 \%$ of respondents $(60.87 \%$ of women and $31.68 \%$ of men) stated that this was needed. While the rest, namely, $7.45 \%$ of respondents $(4.97 \%$ of women and $2.48 \%$ of men), stated that providing equal opportunities to women and men was not needed. From the findings above, it is obtained that most of the respondents stated that women need to be given the same opportunities as men in development activities. This acquisition, if sorted out, shows that there is a greater percentage of women compared to men. Eleventh, respondents' reasons if women need to be given the same opportunities as men in development activities. 
From the results of data processing, it turned out that $51.68 \%$ of respondents $(31.54 \%$ women and 20:14\% men) gave the reason that this was needed because women have the same rights as men. The rest, which is $27.51 \%$ (women $19.46 \%$ and $8.05 \%$ men), mentioned the reason is that the issue of women's empowerment in Indonesian society has become a state doctrine. Furthermore, the other small part, which is $20.81 \%$ (women $14.77 \%$ and $6.04 \%$ men), mentioned the reason that women are the largest part of the population of Indonesia, so it needs to be given equal opportunities in development activities.

From the findings above, it can be said that most respondents gave the reason that if women need to be given the same opportunity in development activities, it is because women have the same rights as men. Furthermore, if sorted between men and women, it turns out that women have a greater percentage of acquisition than men. Twelfth, while for the reasons of respondents whether women need to be given the same opportunity in development activities, based on the results of data processing it is obtained that 50\% $(33.34 \%$ men and $16.67 \%$ women) of the number of respondents who disagree (12 people) give reasons because of a lack of real public policies. The rest, 33.33\% (men 25\% and women $8.33 \%$ ) gave the reason for being time-bound. Moreover, the rest also, $16.66 \%$, said the reason was that women's abilities were limited, and this was stated by $8.33 \%$ of female respondents, as well as male respondents.

From the findings above, it can be said that the reason stated that women do not need to be given equal opportunities in development activities is due to the lack of real public policies, time-bound, and limited women's abilities. The most common is the lack of public policies. Furthermore, when it is sorted between men and women it turns out that men have more percentage than men. Thirteenth, respondents' opinions on gender mainstreaming policies.

From the results of data processing, it was obtained that $70.81 \%(46.58 \%$ women and 24.23 men) mentioned that gender mainstreaming was to set strategic steps to enhance the empowerment of women in developing further. The remaining minority, $12.42 \%$, mentioned that the policy of Gender mainstreaming is to improve attitudes that are full of women initiative, and a small portion, namely $10.56 \%$, said that gender mainstreaming is to improve the physical and intellectual capacity of women, and as many as $6.21 \%$ of respondents did not answer. Gender is setting strategic steps to enhance the empower- 
ment of women and men further. If disaggregated between men and women, the percentage of women is greater than that of men.

Based on the results of research related to the analysis of gender equality in the Lamongan Regency government for more details, it can be seen below as follows: A description of gender equality in population, which includes the economy, labor force participation, and unemployment. The total human development index (HDI) has increased as indicated by the HDI value in 2010 of 65.40 and increased to 71.97 in 2018; while the human development index on male gender shows an increase from 2010 reaching 71.56 and continues to increase to 77.03 in 2018; and the human development index on female gender also showed an increase in 2010 of 58.26 and rose to 67.79 in 2018. This shows that the growth of the women's HDI is less rapid than that of the men's HDI because there are still gaps in development achievements humans between women and men.

Nationally, the development of women still lags behind men. From 2010, the development of men had a "high" status with HDI above 70, while the development of women was still in the range of the 60 s and "moderate" status. The increase in the gender development index (IPG) in this study is progress in terms of gender equality. This progress is caused by the components of women's development continues to grow, but the value is still higher for men. The women's empowerment index (IDG) in this study can show whether women can actively participate in economic life. IDG focuses on participation by measuring gender inequality in the field of decision making and accessibility to economic resources. The level of labor force participation (TPAK), job seekers, and TKI Lamongan Regency in 2013-2018 has increased. This is because the labor force is proxied by the level of labor force participation (TPAK) for men. This is because, with the increase in TPAK, job seekers, and TKI, which means a reduction in the gap between men and women in employment where women are given the freedom and broad opportunities to work.

Description of gender equality in the social field, which includes education and health. The condition of education in the Lamongan Regency based on gender in 2013-2018 has increased every year; this is because gender equality in education has been going well because of efforts to stop gender biases against all aspects of life, among others by addressing the practical needs of gender. The 
main strategy towards gender equality in education is the provision of access to quality education, especially basic education equally for men and women, both through school education and non-school education. The health condition of the Lamongan Regency based on gender has increased from 2013 to 2018. This is because health has an important role in gender equality towards better development and the achievement of gender equality in the health sector. Lamongan Regency's life expectancy (AHH) in 2013-2018 experienced a significant increase; this is because genetically, women have higher health status than men. This is known as female advantages (FA).

The existence of female advantages is related to female hormones and the habits of life of women who are generally considered "healthier" than men. The implication of this is the life expectancy of women, especially in Indonesia, which is always of higher value than men. Although it is different higher annual UHH tendency is a warning for all groups to prepare facilities for the elderly whose numbers are predicted to increase shortly.

\subsection{Results of Respondents Analysis of Gender Equality}

Regarding gender equality views, the results of data processing show that respondents' views are also varied. From the findings above, it turns out that most respondents gave their views that gender equality is equal rights between women and men. And if disaggregated between men and women, it turns out that the acquisition of female respondents is higher than that of men. Regarding the view of gender inequality for respondents, from the findings above, it can be stated that the views of the majority of respondents regarding gender inequality are the powerlessness of women in attitude compared to men. When compared between women and men, it turns out that the percentage of women respondents is also greater than male respondents. To the view of agreeing or disagreeing with the concept of gender equality; from the findings above, it can be obtained that most respondents agree with the concept of gender equality. And when divided between women and men, it turns out that the percentage of female respondents who agree is also greater than that of men. Reasons for agreeing to the existence of the concept of gender; from the findings above, it is obtained that most respondents agree to gender equality because there is a feeling of mutual support 
in all fields between women and men. When compared between respondents. Reasons to agree if women take a lot of work in politics, From the description above it can be said that most UPI students agree if women take part in politics, and nearly half of those who agree are women, and the reasons given for their agreement are mostly due to equality between men and women. While the reasons for disagreeing if women do a lot of work in politics, from the description above, it can be stated that from the number of respondents who disagree most give reasons for disapproval when women take part in politics is because it absorbs a lot of family time. Meanwhile, when compared with women and men, the percentage of men is greater than women. The opinion of the respondent if the wife's income is higher, From the findings above, it can be said that almost half of the respondents stated that they still hoped that the husband would earn more than his wife. Meanwhile, when compared between women and men, it turns out that the percentage of women is greater than that of men. The opinion of the respondent in the case if a woman acts as an official in an agency. From the findings above, it can be said that respondents' answers varied. The most is expressing salute and pride when women become officials in an agency. Furthermore, when divided between women and men, it turns out that the percentage of women is greater than the acquisition of men.

The opinion of the respondent if in a family, the wife has a higher social position than the husband. From the findings above, it can be said that almost all respondents stated that if in a family the wife had a higher social position, she would still hope that the husband remained dominant as the head of the family. Moreover, when disaggregated between women and men, it turns out that the percentage of women is also greater than the percentage of men. In the case of whether or not women need to be given the same opportunities as men in development activities.

From the findings above, it is obtained that most of the respondents stated that women need to be given the same opportunities as men in development activities. This acquisition, if sorted out, turns out to be a greater percentage of women compared to men. Respondents' reasons if women need to be given the same opportunities as men in development activities. From the findings above, it can be said that most respondents gave the reason if women need to be given the same opportunity in development activities because women have the same rights 
as men. Moreover, if it is sorted between men and women, it turns out that the percentage of women is greater than that of men.

While the respondent's reasons if women do not need to be given the same opportunity in development activities, the findings above can be said that the reason stated that women do not need to be given the same opportunity in development activities is due to the lack of real public policies, time-limitations, and limitations of women's abilities. The most common is the lack of public policies. Moreover, when separated between men and women, it turns out that men have more percentage than men.

Respondents' opinions about gender mainstreaming policies. From the description above, it can be stated that the majority of respondents mentioned that gender mainstreaming is determining strategic steps to further enhance the empowerment of women and men. If disaggregated between men and women, the percentage of women is greater than that of men. In addition to explaining the concept of PUG, it is deemed necessary to develop indicators to measure PUG implementation, while also limiting the scope of the substance of the discussion. These indicators are formulated from the definition of PUG contained in Minister of Home Affairs Regulation Number 15 of 2008. The five indicators of implementation of GM in the regions, namely: Regional policies related to KG and PUG. To understand the concept of gender, gender must be distinguished from the word sex (sex). The definition of sex is the division or division of two sexes that are biologically determined to be attached to a particular sex. For example, that men are a type of human who has, among others, a penis, Adam's apple, and produce sperm.

While women have reproductive organs such as the uterus, produce eggs, have a vaginal canal to give birth, and have breastfeeding tools. These tools are biologically attached to human types of women and men forever. This means that biologically the tool cannot be exchanged between biological devices that are attached to human males and females. Permanently unchanged and is a biological provision or often referred to as the provisions of God or nature. The concept of gender is a trait inherent in men and women socially and culturally constructed. For example, that woman is known to be gentle, emotional, beautiful, and motherly (Busanich \& McGannon, 2010). 
While men are considered strong, rational, mighty. Changes in the characteristics of the traits can occur from time to time and from place to place, from social class to other social classes (Sherif, 2015). It could be that in a certain tribe, rural women are considered to be stronger and manage family decisions. While in some decades, men in Java or Asia are considered more powerful than women. So, the inherent nature of gender is not fixed but depends on the culture of society. All things that can be exchanged between the nature of women and men that can change from time to time and different from place to place, or different from one class to another class that is what is known as the concept of gender. History of gender differences between humankind, men, and women, goes through a very long process. Therefore, the formation of gender differences is due to many things, including being formed, socialized, strengthened, and even constructed socially and culturally through religious and state teachings. Through a long process also, the socialization of gender is finally considered a powerful provision (God). It is as if it is biological, which cannot be changed anymore, cannot be exchanged, so that gender differences are considered and understood as the nature of men and the nature of women.

\section{CONCLUSION AND IMPLICATION}

Based on the findings in this study, it can be concluded that in general, the community is quite understanding about the concept of gender, gender equality, and gender mainstreaming. However, when separated between women and men, it seems that women understand more than men. This can be seen from the results of data analysis. In terms of the notion of gender, there are still varied opinions. This indicates that there is still a diverse understanding of the concept of gender. In terms of whether or not they agree with gender equality, there are still those who say disagree even though the number is small at $20.50 \%$, and when compared to that number men are greater $(13.67 \%)$ than women $(6.83 \%)$. This disagreement is due to most men mentioning because women will feel no longer uncomfortable with men. From this, it can be said that there is still a patriarchal culture, which considers women to feel uncomfortable facing men, men should be more authoritative, than women, where it should not have happened if they understood the concept of gender. In the end, it can be said that 
in general, they are conceptually aware of the concept of gender equality or gender mainstreaming, but in reality, their perceptions are still influenced by the culture of male domination.

\section{REFERENCES}

Bhopal, K. 2019. Gender,' race' and patriarchy: a study of South Asian women. Routledge.

Busanich, R. \& McGannon, K.R. 2010. Deconstructing Disordered Eating: A Feminist Psychological Approach to the Body, Food, and Exercise Relationship in Female Athletes. Quest, 62(4), 385-405.

Dhewy, A. 2017. Gender Perspective as Formality: Feminist Policy Analysis toward RPJMN 2015-2019 and Strategic Plan of KPPPA 2015-2019. Jurnal Perempuan, 22(1), 55-64.

DiPrete, T.A. \& Buchmann, C. 2013. The Rise of Women: The Growing Gender Gap in Education and What It Means for American Schools. Russell Sage Foundation.

Grant, J. 2013. Fundamental Feminism: Contesting the Core Concepts of Feminist Theory. Routledge.

Jha, P. \& Nagar, N. 2015. A Study of Gender Inequality in India. The International Journal of Indian Psychology, 2(3), 46-53.

Jones, G.A. \& Chant, S. 2009. Globalizing Initiatives for Gender Equality and Poverty Reduction: Exploring 'Failure' Regarding Education and Work among Urban Youth in the Gambia and Ghana. Geoforum, 40(2), 184-196.

Maxwell, J.A. 2010. Using Numbers in Qualitative Research. Qualitative Inquiry, 16(6), 475-482.

Meier, P. \& Celis, K. 2011. Sowing the Seeds of Its Failure: Implementing the Concept of Gender Mainstreaming. Social Politics, 18(4), 469-489.

Muchtar, A.T., Koban, A.W., Inayatullah, B., Srihadi, E., \& Amelia, L. 2012. Deliberation of the State Budget Bill (RUU APBN) and Border Issues at the DPR: a Current Study on Access to Information and Public Participation.

Nie, J.B. 2010. Limits of State Intervention in Sex-Selective Abortion: The Case of China. Culture, Health \& Sexuality, 12(2), 205-219. 
Okali, C. 2011. Searching for New Pathways towards Achieving Gender Equity: Beyond Boserup and women's Role in Economic Development.

Ombati, V., \& Ombati, M. 2012. Gender Inequality in Education in sub-Saharan Africa. JWEE, (3-4), 114-136.

Sherif, M. 2015. Group Conflict and Co-Operation: Their Social Psychology. Psychology Press.

Windels, K. \& Mallia, K.L. 2015. How being Female Impacts Learning and Career Growth in Advertising Creative Departments. Employee Relations. 
Review of Management and Entrepreneurship

Volume 04, Number 02, October 2020 